AB0477 EFFECT OF ANTI-TNF THERAPY ON BONE MINERAL DENSITY IN ANKYLOSING SPONDYLORTHITIS

A. Ajerouassi ${ }^{1}, \mathrm{~K}$. Nassar ${ }^{1}, \mathrm{~S}$. Janani ${ }^{1} .{ }^{1}$ faculté de médecine et de pharmacie de cabalanca, centre hospitalier universitaire ibn rochd, rhumatologie,

Casablanca, Morocco

Background: Osteoporosis is common in spondyloarthritis, due to reduced spinal mobility, and inflammation. Anti-inflammatory treatments have a beneficial effect on the bone, and there is a significant increase in bone density during treatment with anti-TNF alpha.

Objectives: to study bone mineral density in patients with ankylosing spondyloarthritis (AS) treated with anti-TNF alpha.

Methods: This is a retrospective descriptive study of patients with AS meeting the modified New York criteria. Bone mineral density, assessed by dual energy x-ray absorptiometry (DXA), of AS patients treated with anti-TNF alpha was compared to that of a control group of AS patients not treated with anti-TNF alpha.

Inclusion criteria:

- Male patients

- Patients who do not have an abnormality disrupting phosphocalcic and bone metabolism

- For Patients on anti-TNF alpha: the treatment must be received for more than 6 months

Results: A total of 22 patients were included, including 11 patients on anti-TNF alpha and 11 patients not on anti-TNF. The mean age (standard deviation) was $28( \pm 7.2)$ years and $41( \pm 14.8)$ in the cases and controls respectively. The mean body mass index in the AS group on anti-TNF was $22.16 \mathrm{~kg} / \mathrm{m} 2$ and in the control group was $19.64 \mathrm{~kg} / \mathrm{m} 2$. In the AS group on anti-TNF alpha, the mean bone mineral density of the spine was $1.092 \mathrm{~g}$ $1 \mathrm{~cm} 2$ (mean T score $=-0.63$ ) and that of the femoral neck, the mean bone mineral density was $0.888 \mathrm{~g} / \mathrm{cm} 2$ (mean T score $=-1.04$ ). In the control group, the mean bone mineral density of the spine was $0.959 \mathrm{~g} / \mathrm{cm} 2$ (mean T score $=-1.91$ ) and the mean bone mineral density of the femoral neck was $0.774 \mathrm{~g} / \mathrm{cm} 2$ (mean T score $=-1.99$ ). Bone mineral density in the spine and cervix was higher in the group receiving anti-TNF alpha $(p=0.09, p=0.173$ respectively)

Conclusion: Our study shows the increase, although not statistically significant, in bone mineral density in AS patients receiving anti-TNF alpha agents compared to controls. Our results agree with those of the literature which support the bone protective effect of anti-TNF alpha. The non-significant difference can be explained by the delay in the introduction of biotherapy at the advanced stage of the structural evolution of AS. The best solution is to start TNF inhibitors at the early inflammatory stage of AS.

Disclosure of Interests: None declared

DOI: 10.1136/annrheumdis-2021-eular.2940

\section{AB0478 IN PREVIOUSLY BIOLOGIC-NAÏVE RHEUMATIC PATIENTS WITH DRUG INDUCED LUPUS SECONDARY TO A FIRST ANTI-TNF THERAPY, IS IT SAFE TO SWITCH TO A SECOND ANTI-TNF- $\alpha$ AGENT?}

A. Martins $^{1}$, D. Santos Oliveira ${ }^{1,2}$, F. R. Martins ${ }^{3}$, F. Oliveira Pinheiro ${ }^{1}$, M. Rato ${ }^{1}$, D. Fonseca ${ }^{4}$, S. Garcia ${ }^{1}$, B. M. Fernandes ${ }^{1}$, S. Pimenta ${ }^{1,5}$, M. Bernardes ${ }^{1,5}$, L. Costa ${ }^{1} .{ }^{1}$ Centro Hospitalar Universitário São João, Rheumatology, Porto, Portugal; ${ }^{2}$ Faculdade de Medicina da Universidade do Porto - FMUP, Center for Health Technology and Services Research (CINTESIS), Porto, Portugal; ${ }^{3}$ University Hospital Center of Algarve, Rheumatology, Faro, Portugal; ${ }^{4}$ Centro Hospitalar Vila Nova de Gaia / Espinho - Unit 1, Rheumatology, Porto, Portugal; ${ }^{5}$ Faculdade de Medicina da Universidade do Porto - FMUP, Rheumatology, Porto, Portugal

Background: Drug-induced lupus erythematosus (DILE) secondary to anti-TNF- $\alpha$ agents results from an immunogenicity phenomena not yet fully understood and is a rare condition. Withdrawal of anti-TNF- $\alpha$ therapy usually leads to total resolution of symptoms, however sometimes immunosuppression is needed. It is not clear if this condition is drug specific or class related. Therefore, there are doubts about the safety of switching to a second TNF inhibitor: will a further anti-TNF- $\alpha$ agent increase the risk of DILE recurrence?

Objectives: To analyze the outcomes in patients with DILE secondary to an antiTNF- $\alpha$ agent that switch to a second anti-TNF- $\alpha$ agent.

Methods: We performed a retrospective analysis of patients with spondyloarthritis, psoriatic arthritis and rheumatoid arthritis from our University Hospital, who developed DILE secondary to an anti-TNF- $\alpha$ agent as a first biologic and switch to a second anti-TNF- $\alpha$ agent. Because specific criteria for the diagnosis of DILE have not been established, DILE diagnosis was considered when a temporal relationship between clinical manifestations and antiTNF alpha treatment was found and ACR/EULAR 2019 classification criteria for SLE were fulfilled. Clinical and laboratorial features and outcomes were collected from the Portuguese Rheumatic Diseases Register (Reuma.pt) and medical records.

Results: Six of 617 patients developed DILE secondary to anti-TNF- $\alpha$ agents (2 secondary to etanercept, 2 to adalimumab and 2 to infliximab). These patients had total resolution of symptoms and autoantibodies (ANA and anti-DNAds), induced by the therapy, disappeared after withdrawal of the anti-TNF- $\alpha$ agent implied.

Afterwards, 4 of these 6 patients switched to a second anti-TNF- $\alpha$ agent: 1 to etanercept, 1 to certolizumab, 1 to adalimumab and another to golimumab. The time interval between the two therapies was 2,0 \pm 0,8 months. Regarding the outcomes, in all four patients, no DILE recurrence or autoantibodies induction recurrence was observed. These patients have a good response to the new biotherapy, without side effects reported, and a significant clinical improvement was observed.

Conclusion: Our study results are in agreement with the literature described before. It seems that exist a low rate of DILE recurrence with an alternative antiTNF- $\alpha$ agent. Thus, this condition seems to be drug specific rather than class related. Therefore, it seems secure to use a second anti-TNF- $\alpha$ agent, even in a short period of time after DILE development. There is no evidence about the best or securest second TNF inhibitor, so any anti-TNF- $\alpha$ agent can be prescribed. A carefully monitoring of symptoms of relapse should be ensured. In conclusion DILE secondary to a TNF inhibitor should not be an absolute contraindication to the use of a subsequent anti-TNF- $\alpha$ agent.

Disclosure of Interests: None declared.

DOI: 10.1136/annrheumdis-2021-eular.2992

\section{AB0479 LONGTERM RETENTION RATE OF CERTOLIZUMAB PEGOL IN AXIAL SPONDYLOARTHRITIS IS HIGHER: DATA FROM TURKBIO}

S. S. Koca ${ }^{1}$, Y. Pehlivan ${ }^{2}$, S. Akar ${ }^{3}$, S. Şenel ${ }^{4}$, A. Avanoglu Guler ${ }^{5}$, O. Sosyal ${ }^{6}$, A. Yazici ${ }^{7}$, S. Yılmaz ${ }^{8}$, R. Piskin Sagir ${ }^{1}$, N. Inanc ${ }^{9}$, A. Karatas ${ }^{1}$, G. Yildirim Cetin ${ }^{10}$, P. Atagündüz ${ }^{9}, F$. Onen ${ }^{11}$ on behalf of TURKBIO Study Group. ${ }^{1}$ Firat University School of Medicine, Department of Rheumatology, Elazig, Turkey; ${ }^{2}$ Uludağ University, School of Medicine, Department of Rheumatology, Bursa, Turkey; ${ }^{3}$ Katip Celebi University, School of Medicine, Department of Rheumatology, Izmir, Turkey; ${ }^{4}$ Erciyes University School of Medicine, Department of Rheumatology, Kayseri, Turkey; ${ }^{5}$ Gazi University School of Medicine, Department of Rheumatology, Ankara, Turkey; ${ }^{6}$ Celal Bayar University School of Medicine, Department of Rheumatology, Manisa, Turkey; ${ }^{7}$ Kocaeli University School of MEdicine, Department of Rheumatology, Kocaeli, Turkey; ${ }^{8}$ Selcuk University School of Medicine, Department of Rheumatology, Konya, Turkey; ${ }^{9}$ Marmara University School of Medicine, Department of Rheumatology, Istanbul, Turkey; ${ }^{10}$ Kahramanmaras Sutçu Imam University School of Medicine, Department of Rheumatology, Kahramanmaraş, Turkey; ${ }^{11} 9$ Eylul University School of Medicine, Department of Rheumatology, Izmir, Turkey

Background: Choosing the best treatment strategy for a patient is one of the most difficult issues in modern rheumatology, as there are various factors affecting drug therapy in chronic diseases, such as efficacy, safety, and compliance Physicians take care of long-term retention rate and responses for discontinuation of candidate drug.

Objectives: The purpose of this study to assess the drug survival of certolizumab pegol (CZP) in patients with axial spondyloarthritis (ax-SpA) and to identify the predictors and reasons for discontinuation.

Methods: Data on patient characteristics, demographics, diagnosis, duration of disease, treatment and outcomes have been collected since 2011 in Turkish Biologic (TURKBIO) Registry. By the end of December 2020, 410 ax-SpA patients received CZP and were included. Kaplan Meier plot was used for drug survival analysis. Cox regression analysis was performed to evaluate the predictor associated with drug survival.

Results: During the median 54 months follow-up, 92 (22.4\%) patients discontinued the CZP treatment. The reasons for discontinuation: ineffectivity was $58.7 \%(n=54)$, adverse events was $6.5 \%$, pregnancy was $3.3 \%$ and surgery was $4.3 \%$. The baseline characteristics of patients continue with CZP and discontinuation due to ineffectiveness were shown in the Table 1. Patients who discontinued CZP had higher HAQ, BASFI and BASDAI values. Moreover, they were more co-treated with NSAIDs and csDMARDs At the month 36 , retention rate of CZP was $71.5 \%$ in patients with ax-SpA (Figure 1). 